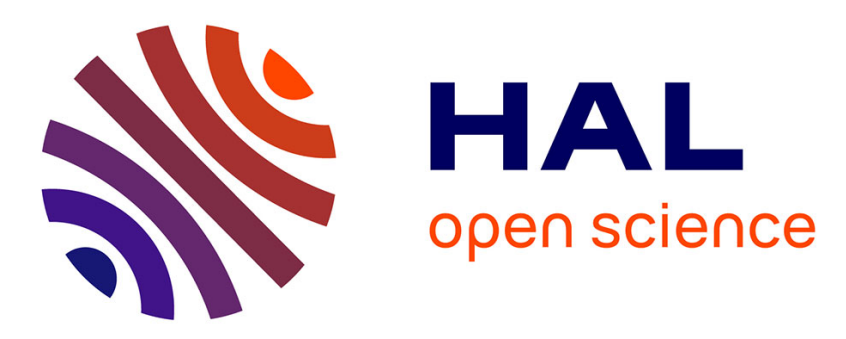

\title{
Vibration-induced instability of a fluid film flowing down a vertical plane: Experimental and numerical comparison
}

Shimon Julius, Henri Garih, Jean-Luc Estivalezes, Grégoire Casalis

\section{- To cite this version:}

Shimon Julius, Henri Garih, Jean-Luc Estivalezes, Grégoire Casalis. Vibration-induced instability of a fluid film flowing down a vertical plane: Experimental and numerical comparison. Physics of Fluids, 2019, 31 (10), pp.104111. 10.1063/1.5112098 . hal-02794110

\section{HAL Id: hal-02794110 \\ https://hal.science/hal-02794110}

Submitted on 5 Jun 2020

HAL is a multi-disciplinary open access archive for the deposit and dissemination of scientific research documents, whether they are published or not. The documents may come from teaching and research institutions in France or abroad, or from public or private research centers.
L'archive ouverte pluridisciplinaire HAL, est destinée au dépôt et à la diffusion de documents scientifiques de niveau recherche, publiés ou non, émanant des établissements d'enseignement et de recherche français ou étrangers, des laboratoires publics ou privés. 


\title{
Vibration-induced instability of a fluid film flowing down a vertical plane: Experimental and Numerical Comparison
}

\author{
S. Julius, ${ }^{1, \text { a) }}$ H. Garih, ${ }^{1, b)}$ J.L. Estivalezes, ${ }^{1, c)}$ and G. Casalis ${ }^{1, d)}$ \\ ONERA, The French Aerospace Lab, 2 avenue Edouard Belin, \\ 31055 Toulouse cedex 4, France
}

This paper constitutes the final part of an investigation into the vibration-induced instability of a fluid flowing down an inclined plane. The first part ( Vibration-induced instability of a fluid film flowing down a vertically inclined plane: Experimental and theoretical comparison." Physics of Fluids 29.10 (2017): 104103.) involved validating the theory of linear stability as applied to a fluid flowing down a vertically inclined plane via experimental comparison. In this second part, a two-dimensional direct numerical simulation is carried out, and is compared to experiment. The numerical solver was compared to experiment by evaluating the frequency spectra at specific forcing amplitudes where mode $2 \& 3$ instabilities become dominant. The simulation reproduced the frequency spectra in all cases to a high degree of accuracy and demonstrates that a consideration of a two-dimensional case is sufficient to accurately resolve the onset and growth of higher mode non-linear instabilities without the need to account for three-dimensional effects.

\footnotetext{
a)Electronic mail: shimonjulius@campus.technion.ac.il

b)Electronic mail: henri.garih@onera.fr

c) Electronic mail: jean-luc.estivalezes@onera.fr

d)Electronic mail: gregoire.casalis@onera.fr
} 


\section{INTRODUCTION}

Since it was first studied by Faraday ${ }^{1}$ almost 190 years ago, the hydrodynamic instability of well-ordered spatial patterns that form as a result of a periodic forced vibration have become the subject of extensive theoretical research. Recent advances in computational performance have allowed a complete simulation of the full non-linear problem. In their two-dimensional simulations, Murakami \& Chikano ${ }^{2}$, addressed the problem of numerical simulation of an oscillating fluid. The work of Chen $\& \mathrm{Wu}^{3}$ and $\mathrm{Chen}^{4}$, focused their studies on the non-linear wave dynamics resulting from such a forcing. Valha, Lewis \& Kubie ${ }^{5}$ performed a study into the gas-liquid interface. Ubal, Giavedoni \& Saita ${ }^{6}$ did a numerical analysis on the influence of fluid depth on Faraday waves. Together, their work provides a comprehensive picture of the two-dimensional numerical simulation of a horizontal container subject to vertical oscillation.

A recent study into three-dimensional patterns by Perinet, Juric \& Tuckerman ${ }^{7}$ incorporated three-dimensional effects into the numerical solution. The simulation solved the Navier-Stokes equations through a finite-difference projection method, coupled with a front tracking method to capture the liquid-gas interface.

The numerical simulation section of this study is adapted from the three-dimensional Navier-Stokes numerical solver developed by Couderc ${ }^{8}$ and validated by Trontin et al ${ }^{9}$. The solver was modified by Garih, Estivales \& Casalis ${ }^{10}$ to simulate a vibration-induced instability. This model couples a finite difference projection method with a level-set method to allow the interface dynamics to be captured. In this study, the solver is adapted to consider the two-dimensional problem of a fluid flowing down an inclined plane subject to periodic oscillation, with flowing air at the interface boundary.

A large number of experimental studies have been carried out better to understand fluid behaviour or a static fluid bounded in a vessel. Douady ${ }^{11}$ produced one of the earliest and most complete works on the subject, in which a forced vibration is applied to a squarebottomed vessel containing a liquid film. The non-linear interactions between interacting modes were further studied by Gollub \& Meyer $^{12}$, Ciliberto \& Gollub ${ }^{13}$ and Simonelli \& Gollub $^{14}$. Experimental studies into the onset of spatio-temporal chaos were performed by Ezerskii et $a l^{15}$, Tufillaro et $a l^{16}$, Gollub ${ }^{17}$, Gluckman et al ${ }^{18}$ and Bosch \& van de Water ${ }^{19}$. Christiansen et al ${ }^{20}$ Edwards \& Fauve $^{21}$ and Muller ${ }^{22}$ carried out experiments to shed light 
on stationary pattern formation. Building on these findings, Bechhoefer et al ${ }^{23}$ deepened the investigation of surface waves resulting from the Faraday instability.

Garih et $a l^{24}$ conducted the first experiments of a fluid flowing down a vibrating inclined plane. In their study, two experiments of a fluid flowing down a vertical plane were performed. In the first, the entire plane was vibrated. In the second, only a small portion of

the fluid was vibrated. The two forcing techniques were shown to be similar. The latter also confirmed the validity of the theory of linear stability in predicting the behaviour of the flow before the onset of the mode 2 instability.

This study builds on the second experiment carried out by Garih et al ${ }^{24}$, adding an air flow to generate a shear force at the air-fluid interface. The amplitudes of transition between different mode instabilities were found, and the frequency spectra of the experiment and the two-dimensional DNS were compared.

Beginning with an overview of the numerical simulation and grid convergence, the study will then move to outline the experimental set-up and procedure. The experimental results and numerical simulation will then be compared.

\section{NUMERICAL SIMULATION}

\section{A. Geometry and governing equations}

This study considers an incompressible Newtonian liquid (water), flowing down a horizontally oscillating vertically inclined plane. This plane is surrounded by air, at ambient conditions, flowing down wards at a speed of $17 \mathrm{~m} / \mathrm{s}$. The oscillation of the vessel is characterised by a sinusoidal waveform of amplitude $A$ and angular velocity $\omega$ normal to the vertical plane. In an initial case, it is subject to a forcing frequency of $60 \mathrm{~Hz}$. The dimensions of the simulation environment are a plane of $10 \mathrm{~cm}$ in length, the film of water has a depth of $300 \mu m$ and the surrounding air a boundary layer thickness of $1.5 \mathrm{~mm}$ (see FIG 1). The frame of reference is taken to be the moving plane. As a result, the oscillation dynamic features as a source term in the governing equations. The governing Navier-Stokes equations of liquid motion are therefore as follows:

$$
\left\{\begin{array}{l}
\partial_{t} \underline{V}+\underline{V} \cdot \underline{\underline{\nabla V}}=-\frac{1}{\rho} \underline{\nabla} P+\nu \Delta \underline{V}+\underline{g}-\underline{\hat{A}}(t) \\
\underline{\nabla} \cdot \underline{V}=0
\end{array}\right.
$$




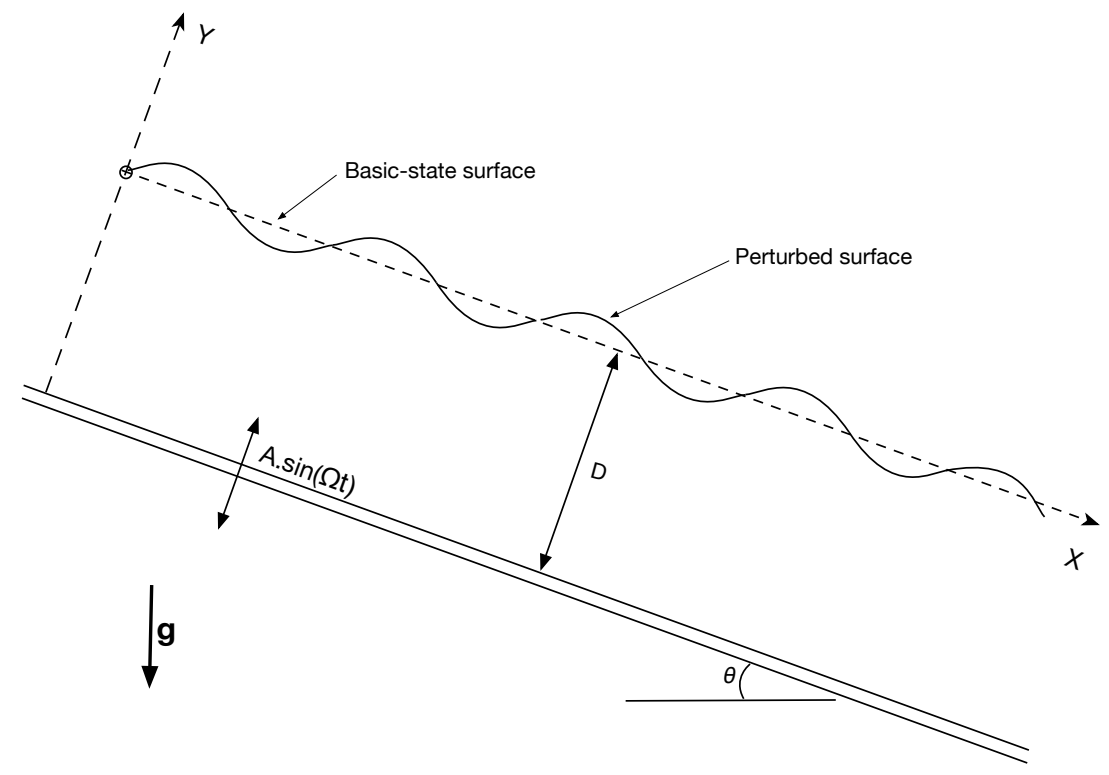

FIG. 1. Diagram of the theoretical model, main notations and coordinates system

where $t$ is time, $\underline{V}$ the velocity vector, $\rho$ the density, $P$ the pressure, $\nu$ the kinematic viscosity, $\underline{g}$ the gravitational acceleration and $\underline{\hat{A}}(t)$ the acceleration associated with the inertial force :

$$
\underline{\hat{A}}(t)=A \Omega^{2} \sin (\Omega t) \underline{e}_{y}
$$

Partial derivation with respect to any variable $\xi$ is denoted by $\partial_{\xi}$.

The boundary conditions associated to these equations are a non-slip condition at the contact of the plane and the dynamic conditions at the free surface. The tangential velocity across the plane is assumed to be continuous. On the outer boundary of the air layer, the normal constraint is set to zero in order to mimic an infinite layer of flowing air.

\section{B. Level-set \& Ghost fluid methods}

The methods used to perform the two-dimensional DNS are similar to those used by Garih, Estivales \& Casalis ${ }^{10}$, in their three-dimensional simulation of a fluid film in a vertically oscillating container. The methodology involved is reminded here.

\section{Level-set method}

A level-set method ${ }^{25}$ is applied in order to solve for the flow at the interface. This is given implicitly by the zero of a smooth function $\phi(\underline{x}, t)$, which is imposed as the signed 
usual distance function to the interface. This function is taken to be positive in the liquid phase, and negative in the gas phase. The normal to the level-set function $\underline{n}$ is defined to always point in the direction of the liquid phase. The development of the interface is solved the implicitly by the zero-level of the level-set function:

$$
\phi_{t}+(\underline{V} \cdot \nabla) \phi=0
$$

The momentum equation is obtained by solving a $5^{\text {th }}$ order conservative WENO scheme for spatial discretisation and a $3^{r d}$ order TVD Runge-Kutta scheme of the level-set equation. The level-set is regularly re-initialised by solving the following Hamilton-Jacobi equation:

$$
\begin{aligned}
& \phi_{t}=\operatorname{sign}\left(\phi_{0}\right)(1-\|\nabla \phi\|) \\
& \phi(x, y, 0)=\phi_{0}(x, y)
\end{aligned}
$$

This equation is then solved by a Godunov type scheme, along with a $5^{\text {th }}$ order conservative WENO scheme. The distance level set can then be re-initialised in the vicinity of the interface in a small number of pseudo-time steps.

\section{Ghost fluid method}

As previously hinted, the difficulty of a numerical simulation across a liquid - gas interface lies in the discontinuous properties of the two phases across the interface. The Ghost fluid method allows for a discontinuous numerical solution, thus greatly improving the validity of the interface capture as compared to a smooth function method, where the solution is spread along multiple cells. In this method, the surface tension is explicit, affording a better approximation to the physical situation.

The Ghost fluid method, the complete mathematical tools of which are set out by Kang $\& \mathrm{Liu}^{26}$, operates by prolongation of the solution of interface position. This allows the interface to be shifted on these virtual points, allowing for a calculation of the local discrete derivative, which would otherwise be impossible. A similar reasoning applies to a derivative

jump across the interface. This process can be applied for the velocity derivatives and the pressure jump. 


\section{Grid definition}

A two-dimensional rectangular grid is adopted. In order to determine the number of grid points required, an estimation of the length of the mode 1 surface wave was performed with

the theory of linear stability, which was confirmed by Garih et al ${ }^{24}$ to apply in this case. The grid is then defined to contain at least ten grid points per wavelength, up to a fixed distance in the $x$-axis of $10 \mathrm{~cm}$ and at least 15 grid points in both the liquid phase and the gas phase.

\section{Frequency, wavelength and growth rate calculation}

Given that the experimental results allow for a comparison of surface wave frequency and wavelength, these are the parameters of interest in the numerical simulation. Much in the same way as the experimental analysis, the frequency is calculated by performing an FFT of the vertical displacement of the surface wave at a "well chosen" point on the interface. The product is a frequency spectrum which can be directly compared to the experimentally determined frequency spectrum and appropriately non-dimensionalised.

The spacial wavelength of the surface wave is simply assessed by identifying the number of wavelengths in a given distance in the $x$ - axis.

The growth rate, being a sensitive parameter, is used to confirm that the grid is converged. It is found through a linear regression of the natural logarithm of the FFT height of each peak of the mode 1 frequency in the linear phase. By reconstruction of the signal obtained and subtracting it from the original signal, the error in the calculation can be obtained.

\section{E. Grid convergence}

The grid is composed of square cells. Previous studies with the same solver ${ }^{10}$ established that 15 grid points are sufficient to fully capture the water film, whose thickness was experimentally determined to be $0.6 \mathrm{~mm}$. The air flow ejected through the outlet was fully characterised, as will later be described, and was found to have a boundary layer thickness of $1.5 \mathrm{~mm}$. In order to capture the entirety of the boundary, the height of the grid is 128 cells. The length of the grid is set to 512 cells, equivalent to $20 \mathrm{~mm}$ in length. This ensures a length greater than one wavelength, as was confirmed experimentally. 
Grid convergence is checked by repeating the simulation with the same parameters, at different mesh refinements. The wavelength and frequency of the surface waves are then compared at the same positions in the flow, and the growth rate is checked. The simulation shows a difference in growth rate of less than $0.7 \%$ over a refinement factor of $4(32 \times 128$ to $128 \times 512$ ) thus, it is clear that the grid of $128 \times 512$ is converged.

\section{EXPERIMENTAL METHODS}

The numerical simulation previously outlined considers the case of a vertically inclined plane, down which a fluid film is flowing, subjected to a uniform synchronous periodic oscillation. Due to the experimental constraints involved in subjecting the film to a known laminar air flow profile, the plane must necessarily be fixed. As shown by Garih et al ${ }^{24}$ an experimental set up identical to the simulation set up without air is quasi-identical to an experimental set-up where the plane remains fixed and the a small portion of the fluid is vibrated through a thin membrane. It is thus reasonable to assume that with blowing air, the two experiments should afford similar results.

\section{A. Experimental Set-up}

The experimental set-up, as depicted in FIG. 2, is composed of a vertically inclined plane, on which a fluid film is flowing. A direct periodic oscillation is applied to a small up-stream portion of the flow. Air is ejected from an opening vertically above the inclined plane. The plane is built of a clear perspex block, riveted to a vertical support rig. A small channel, cut out of an upper portion of the perspex plaque, houses a square oscillating head. The head transmits the forced oscillations produced by a shaker (made by ONERA) to the outer surface of the perspex plaque, through a thin membrane. The shaker is powered by an ONERA power amplifier, which receives a signal from an Agilent 33220A signal generator. The shaker was found to produce a clear horizontal acceleration waveform (lateral oscillation $<<1 \%$ ).

A Micropump Digital Gear pump ( $<1 \%$ flow velocity fluctuation) is used to pump a solution of $0.1 \mathrm{~g} / \mathrm{L}$ Methyl blue to the top of the perspex plaque, where an injector diffuses a thin film $(4 \mathrm{~cm} \times 600 \mu \mathrm{m})$ across the surface of the plaque. Ridges either side of the plaque 


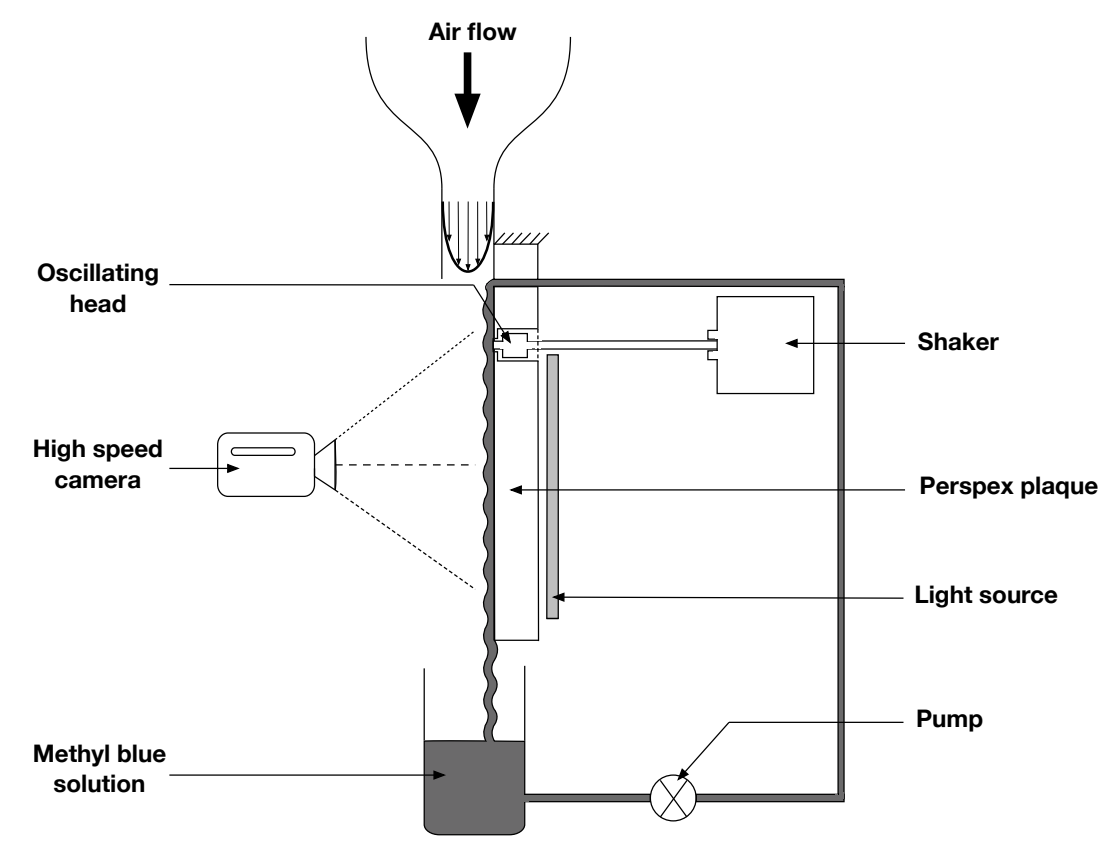

FIG. 2. Experimental set-up

aid the fluid film to attach along the entire width of the channel.

Above the injection slit is positioned the square $(4 \mathrm{~cm} \times 4 \mathrm{~cm})$ air outlet. The air is passed through honeycomb and turbulence reduction screens before entering a settling chamber and passing through a contraction zone. It exits with a laminar flow profile (see FIG. 3), fully characterised by hotwire anemometry, with a mean flow velocity of $17 \mathrm{~m} / \mathrm{s}$.
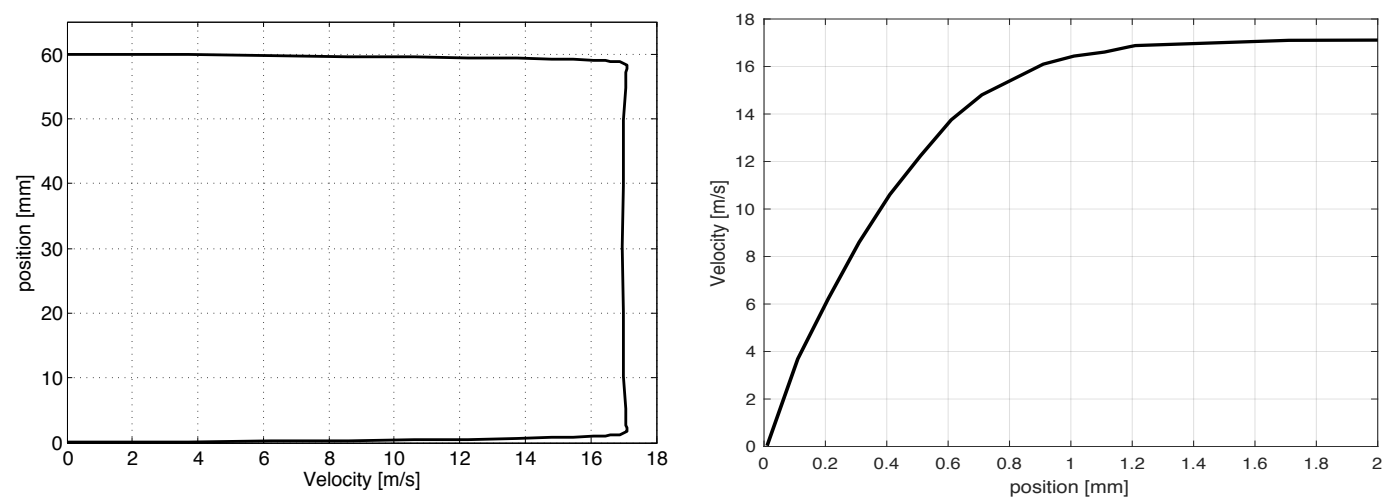

FIG. 3. Flow velocity profile

The perspex plaque is uniformally illuminated from behind, allowing sufficient backlighting to generate high contrast monochromatic images with a 341A Series Phantom high speed camera. The camera is positioned to capture the flow downstream of the oscillating head, 
with a capture area of $608 \times 900$ pixels, an exposure time of $100 \mu s$ at a capturing frequency of $3700 \mathrm{~Hz}$.

A polytec CLV 700 laser vibrometer, aimed at the oscillating head provides a measure of oscillating amplitude and frequency.

\section{B. Data acquisition and analysis techniques}

The methods for experimental data acquisition are identical to those used by Garih et $a l^{24}$. The central methods are be reminded here.

The oscillation amplitude measurements are carried out using the laser vibrometer readings of the head oscillations.

A Fast Fourier Transform (FFT) at a "well chosen" point in the flow is taken, giving a power - frequency spectrum of the surface waves. This "well chosen" point is determined to be in a region of the flow where the oscillatory behaviour is clearly visible and is undistorted by interference at the flow boundaries or by the significant instability of the flow far downstream.

The prevailing wavelength of the surface wave was found by considering the flow along a vertical streamline, taking into account the same precautions, as previously mentioned, in determining a suitable region of the flow.

\section{EXPERIMENTAL COMPARISON WITH THE NUMERICAL SIMULATIONS}

In order to validate thoroughly the numerical simulation, an initial experimental characterisation of the instability variation with amplitude was performed. The amplitudes at which mode $2 \& 3$ instabilities became dominant were then selected to validate the simulation (see Table I). This allows an assessment of the accuracy of the simulation in predicting the transition amplitudes. The range of amplitudes across which these mode transitions occur, is small. 


\begin{tabular}{|c|c|c|c|}
\hline Case & Frequency $[\mathrm{Hz}]$ & Amplitude $[\mathrm{mm}]$ & Dominant mode \\
\hline \hline 1 & $60 \mathrm{~Hz}$ & 0.1295 & 1 \\
\hline 2 & & 0.1347 & 2 \\
\hline 3 & & 0.1399 & 3 \\
\hline 4 & $150 \mathrm{~Hz}$ & 0.1576 & 1 \\
\hline 5 & & 0.1832 & 2 \\
\hline
\end{tabular}

TABLE I. Cases for Experimental \& Numerical comparison

\section{A. Development of instabilities at $60 \mathrm{~Hz}$}

The experimental results in FIG. 4 show a clear peak at $30 \mathrm{~Hz}$, corresponding to an instability at half the forcing frequency. This is the mode 1 instability. Several other distinct peaks are observed at this amplitude, including peaks at 15, 45, 60, 75, 90 and $120 \mathrm{~Hz}$. These correspond to the harmonics of the mode 1 instability as they exhibit an exponential decrease in strength away from $30 \mathrm{~Hz}$. By contrast, the mode 1 instability in this case presents at a slightly higher frequency $(32 \pm 0.6 \mathrm{~Hz})$. The peaks of the harmonics, though seemingly still present, are shifted in the same manner as the mode 1 instability. A comparison at the onset of the mode 2 instability in FIG. 5 shows clearly that the same
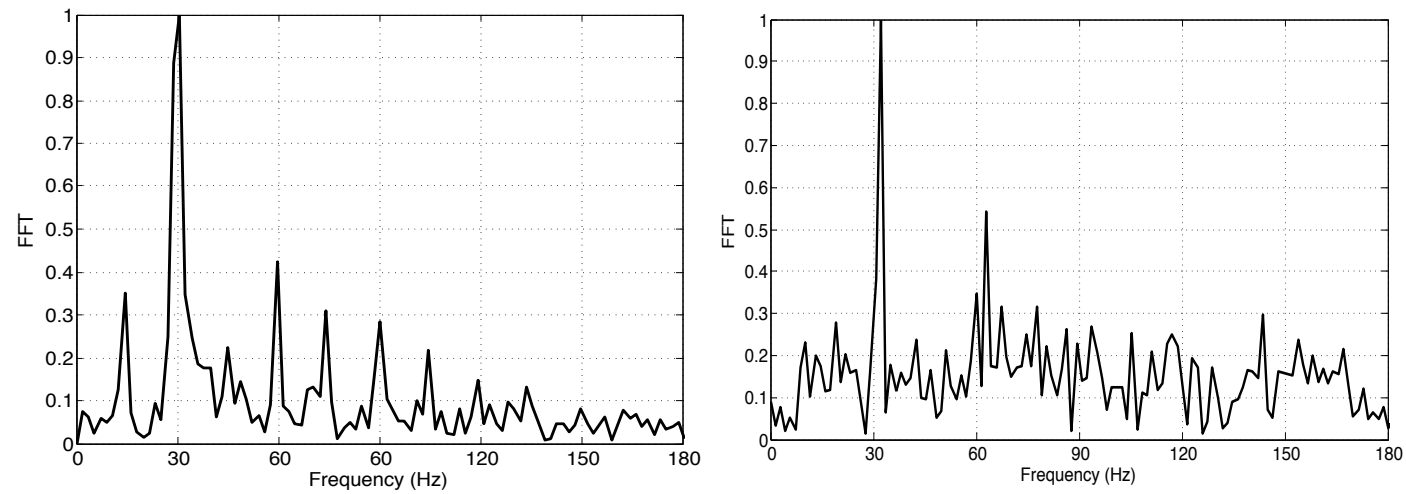

FIG. 4. Experimental (left) and Numerical (right) non-dimensionalised frequency spectra for case $1(60 \mathrm{~Hz}$, mode 1dominiant). Error $\pm 0.6 \mathrm{~Hz}$.

principal peaks are observed. It is worth noting that at the onset of the mode 2 instability, the peaks at $30 \mathrm{~Hz}$ and $90 \mathrm{~Hz}$ are of comparable height. The same pattern in the frequency spectrum is also found when comparing the onset of the mode 3 instability in FIG. 6. 

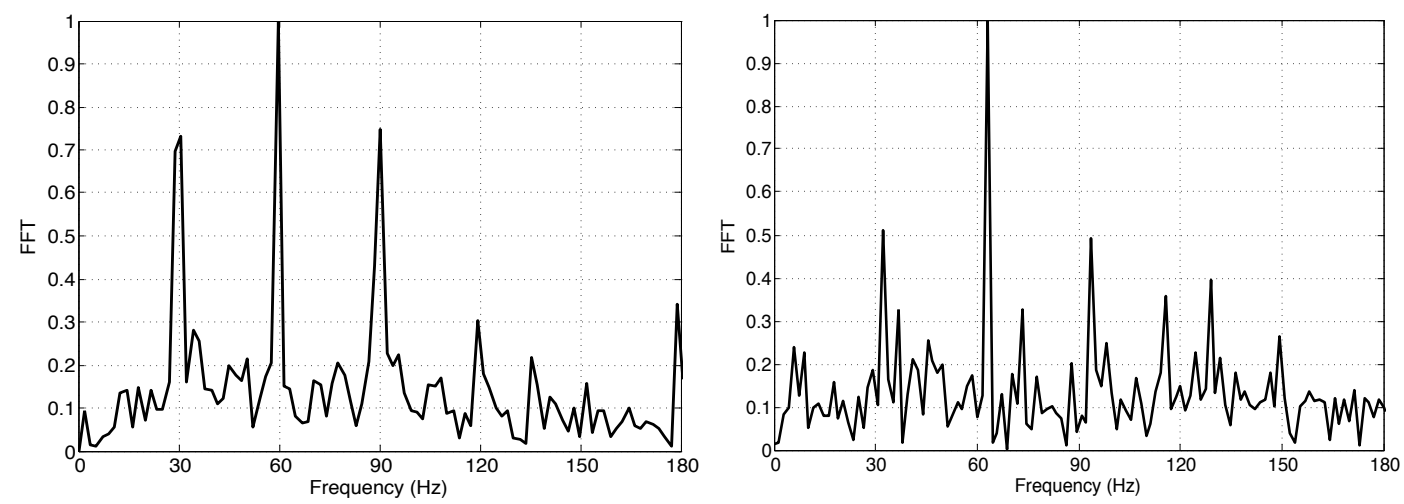

FIG. 5. Experimental (left) and Numerical (right) non-dimensionalised frequency spectra for case $2(60 \mathrm{~Hz}$, mode 2 dominiant). Error $\pm 0.6 \mathrm{~Hz}$.

Contrary to experimental findings, the peaks from the two-dimensional simulation show the same frequency shift previously observed. This shift increases with frequency, and is well predicted in the theory of linear stability when considering a two-dimensional case ${ }^{27}$. It is therefore a result of the two-dimensional nature of the numerical simulation, amounting to a systematic error associated to the absence of mesh three-dimensionality.
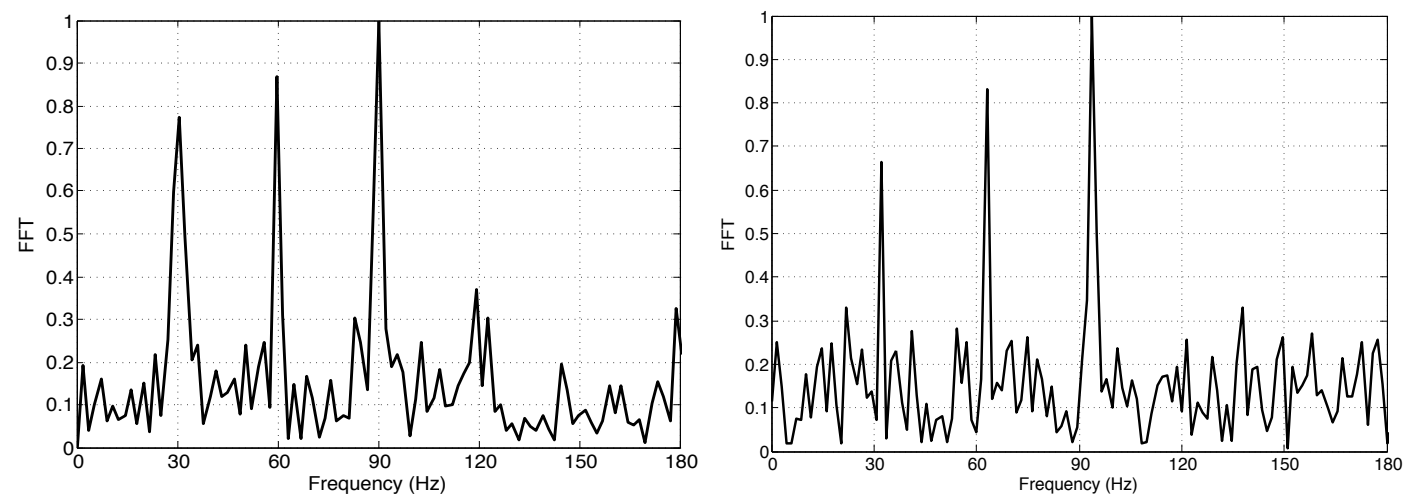

FIG. 6. Experimental (left) and Numerical (right) non-dimensionalised frequency spectra for case $3(60 \mathrm{~Hz}$, mode 3 dominiant). Error $\pm 0.6 \mathrm{~Hz}$.

\section{B. Development of instabilities at $150 \mathrm{~Hz}$}

The simulation is comparably accurate at predicting the peaks of the mode 1 and onset of mode 2 instabilities at a forcing frequency of $150 \mathrm{~Hz}$. In FIG. 7, the mode 1 peaks are clearly observed in the frequency spectrum. At the onset of mode 2, as shown in FIG. 8 , the 

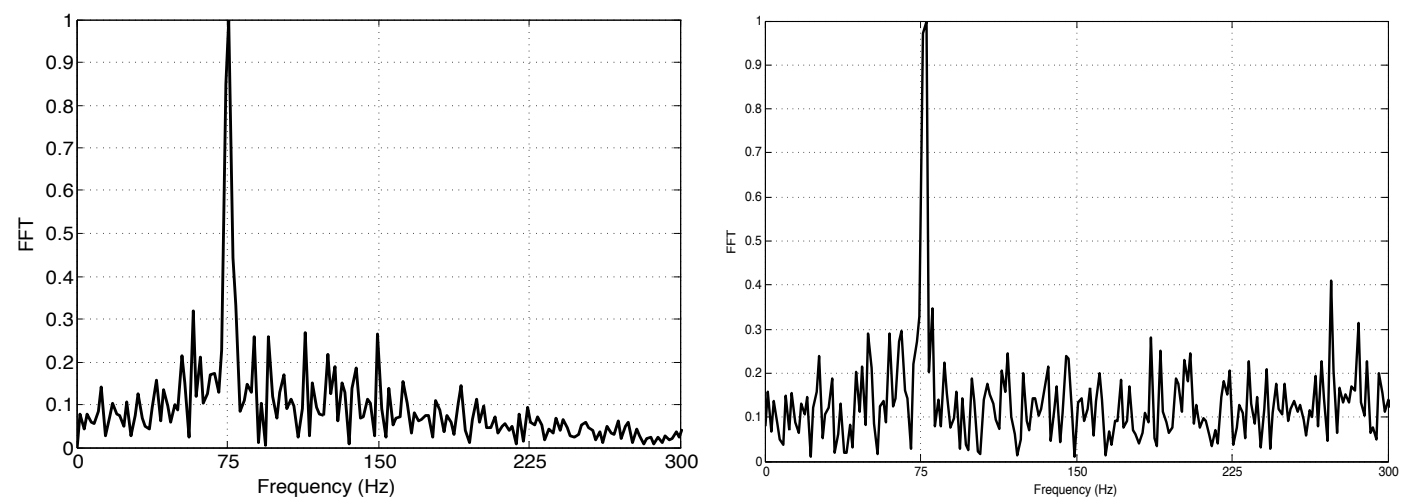

FIG. 7. Experimental (left) and Numerical (right) non-dimensionalised frequency spectra for case $4(150 \mathrm{~Hz}$, mode 1 dominiant). Error $\pm 0.6 \mathrm{~Hz}$.

simulation correctly reproduces the frequency spectrum of the experiment, correctly showing an equal prevalence of both the mode 1 and mode 2 frequencies .
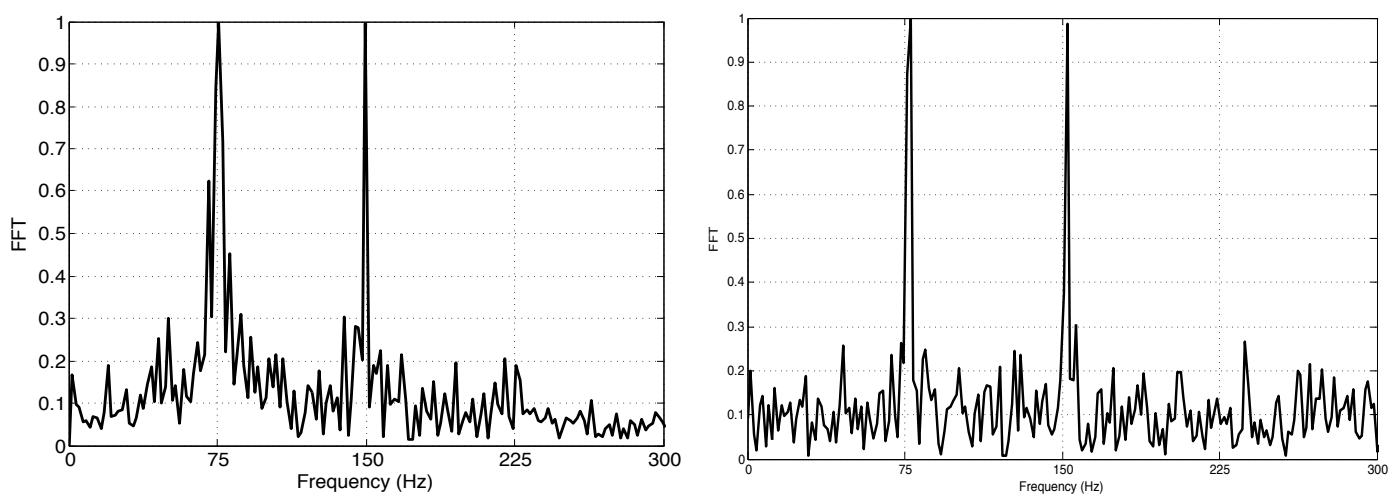

FIG. 8. Experimental (left) and Numerical (right) non-dimensionalised frequency spectra for case $5(150 \mathrm{~Hz}$, mode 2 dominiant). Error $\pm 0.6 \mathrm{~Hz}$.

This remarkable result indicates that three-dimensionality is not a necessary component in the simulation of the onset and growth of the non-linear higher modes in such flows.

\section{CONCLUSION}

The adopted method of two-dimensional numerical simulation can faithfully reproduce the experimental findings. The solver's capability to correctly simulate the mode transitions at various forcing frequencies demonstrates the aptitude of 2-D numerical techniques to the prediction of low-frequency forcing effects on the flow and a sensitivity to small changes 
in amplitude. There is a slight shift of each peak in the frequency spectrum due to twodimensional effects, though this is predicted theoretically to occur, and results in a marginal shift in the frequency content of the simulation.

\section{ACKNOWLEDGEMENTS}

This work has been supported by French Region Midi Pyrénées and ONERA, The French Aerospace Lab.

\section{REFERENCES}

${ }^{1} \mathrm{M}$. Faraday, On the forms and states assumed by fluids in contact with vibrating elastic surfaces, (Phil. Trans. Roy. Soc. Lond. 319-340 (1831)).

${ }^{2}$ Y. Murakami and K. Chikano, Two-dimensional direct numerical simulation of parametrically excited surface waves in viscous fluid, (Phys. Fluids 13, 65-74 (2001)).

${ }^{3}$ P. Chen and K.-A. Wu, Subcritical bifurcations and nonlinear balloons in Faraday waves, (Phys. Rev. Lett. 85, 3813-3816 (2000)).

${ }^{4} \mathrm{P}$. Chen, Nonlinear wave dynamics in Faraday instabilities, (Phys. Rev. E65, 036308 (2002)).

${ }^{5}$ J. Valha, J. S. Lewis and J. Kubie, A numerical study of the behaviour of a gas-liquid interface subjected to periodic vertical motion, (Intl. J. Numer. Meth. Fluids 40,697-721 (2002)).

${ }^{6}$ S. Ubal, M. D. Giavedoni and F. A. Saita, A numerical analysis of the influence of the liquid depth on two-dimensional Faraday waves, (Phys. Fluids 15, 3099-3113 (2003)).

${ }^{7}$ N. Perinet, D. Juric and L. S. Tuckerman, Numerical simulation of Faraday waves, (J. Fluid Mech. 635, 1-26 (2009)).

${ }^{8} \mathrm{~F}$. Couderc, Développement d'un code de calcul pour la simulation d'écoulements de fluides non miscibles. Application à la désintégratin assistée d'un jet liquide par un courant gazeux, (Phd thesis, ISAE (2007)).

${ }^{9}$ Trontin, Pierre, Stephane Vincent, Jean-Luc Estivalezes, and Jean-Paul Caltagirone. "Detailed comparisons of front-capturing methods for turbulent two-phase flow simulations." International journal for numerical methods in fluids 56, no. 8 (2008): 1543-1549. 
${ }^{10}$ Garih, Estivales \& Casalis. On the transient phase of the Faraday instability, (Phys. Fluids 25, 124104 (2013)).

${ }^{11}$ S. Douady (1990). Experimental study of the Faraday instability. Journal of Fluid Mechanics, 221, pp 383-409 doi:10.1017/S0022112090003603

${ }^{12}$ Gollub, J. P. \& Meyer, C. W. 1983 Symmetry breaking instabilities on a fluid surface. Physica D 6, 337-346.

${ }^{13}$ Ciliberto, S. \& Gollub, J. P. 1985 Chaotic mode competition in parametrically forced surface waves. J. Fluid Mech. 158, 381-398.

${ }^{14}$ Simonelli, F. \& Gollub, J. P. 1989 Surface wave mode interactions: effects of symmetry and degeneracy. J. Fluid Mech. 199, 471-494.

${ }^{15}$ Ezerskii, A. B., Korotin, P. I. \& Rabinovich, M. I. 1985 Random self-modulation of twodimensional structures on a liquid surface during parametric excitation. Zh. Eksp. Teor. Fiz.41, 129-131 (transl. 1986 Sou. Phys. JETP 41, 157-160).

${ }^{16}$ Tufillaro, N. B., Ramshankar, R. \& Gollub, J. P. 1989 Order-disorder transition in capillary ripples. Phys. Rev. Lett. 62, 422-425.

${ }^{17}$ Gollub J., P. 1991 Nonlinear waves: dynamics and transport. Physica D 51, 501-511.

${ }^{18}$ Gluckman, B. J., Marcq, P. Bridger, J. \& Gollub J,. P. 1993 Time averaging of chaotic spatiotemporal wave patterns. Phys. Rev. Lett. 71, 2034-2037.

${ }^{19}$ Bosch, E. \& Water, W. Van de 1993 Spatiotemporal intermittency in the Faraday experiment. Phys. Rev. Lett. 70, 342G3423.

${ }^{20}$ Christiansen B., Alstrom, P. \& Levinsen, M. 1992 Ordered capillary-wave states: quasicrystals, hexagons, and radial waves. Phys. Rev. Lett. 68,2157-2160.

${ }^{21}$ Edwards, W. S. \& Fauve, S. 1993 Parametrically excited quasicrystalline surface waves. Phys. Rev. E 47, 788-791.

${ }^{22}$ Muller, H. W. 1993 Periodic triangular patterns in the Faraday experiment. Phys. Rev. Lett. 71, 3287-3290.

${ }^{23}$ Bechhoefer, John, Valerie Ego, Sebastien Manneville, \& Brad Johnson. "An experimental study of the onset of parametrically pumped surface waves in viscous fluids." Journal of Fluid Mechanics 288 (1995): 325-350.

${ }^{24}$ Garih, Julius, Estivales \& Casalis. Vibration-induced instability of a fluid film flowing down a vertically inclined plane: Experimental and theoretical comparison,(Phys. Fluids 29, 104103 (2017)). 
${ }^{25}$ M. Sussman, J. Comput. Phys., 114:144-159 (1994).

${ }^{26}$ M. Kang, R. F. and Liu, X.-D., "A Boundary Condition Capturing Method for Multiphase Incompressible Flow," Journal of Scientific Computing, Vol. 15, 2000, pp. 143-173.

${ }^{27}$ H. Garih, A. Strzelecki, G. Casalis and J. L. Estivalezes, Detailed analysis of the vibration induced instability of a liquid film flow, (Phys. Fluids 25, 014101 (2013)). 
$T_{r}$ 
Oscillating head

High speed camera

Methyl blue solution

Air flow

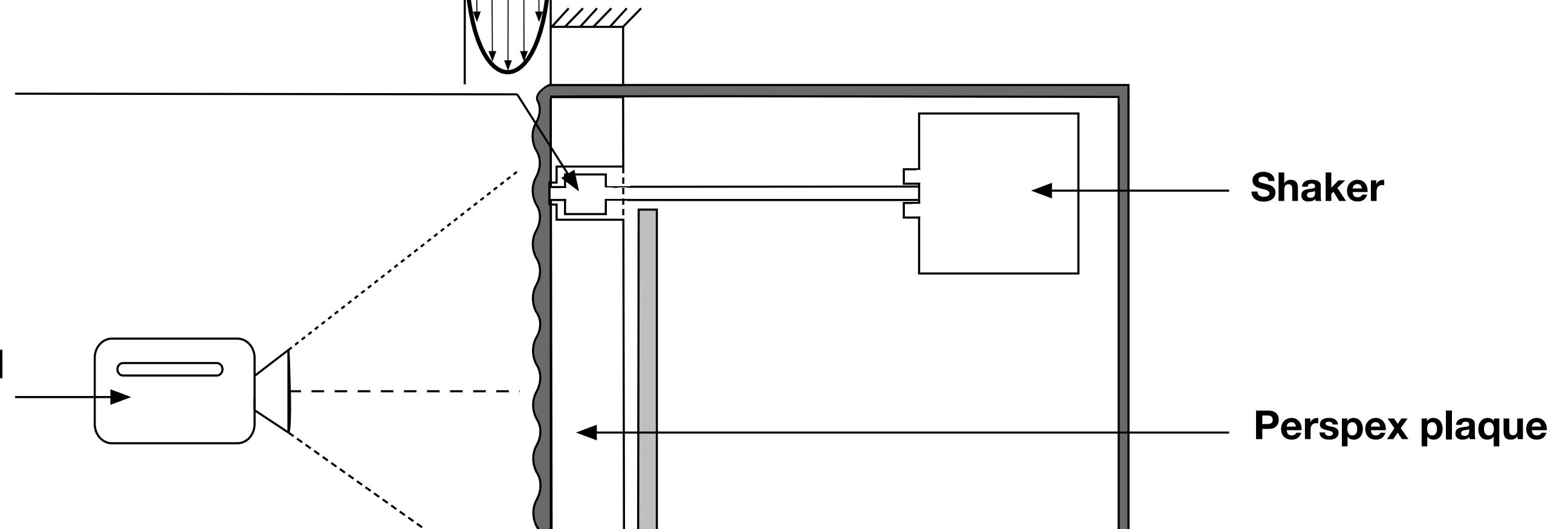




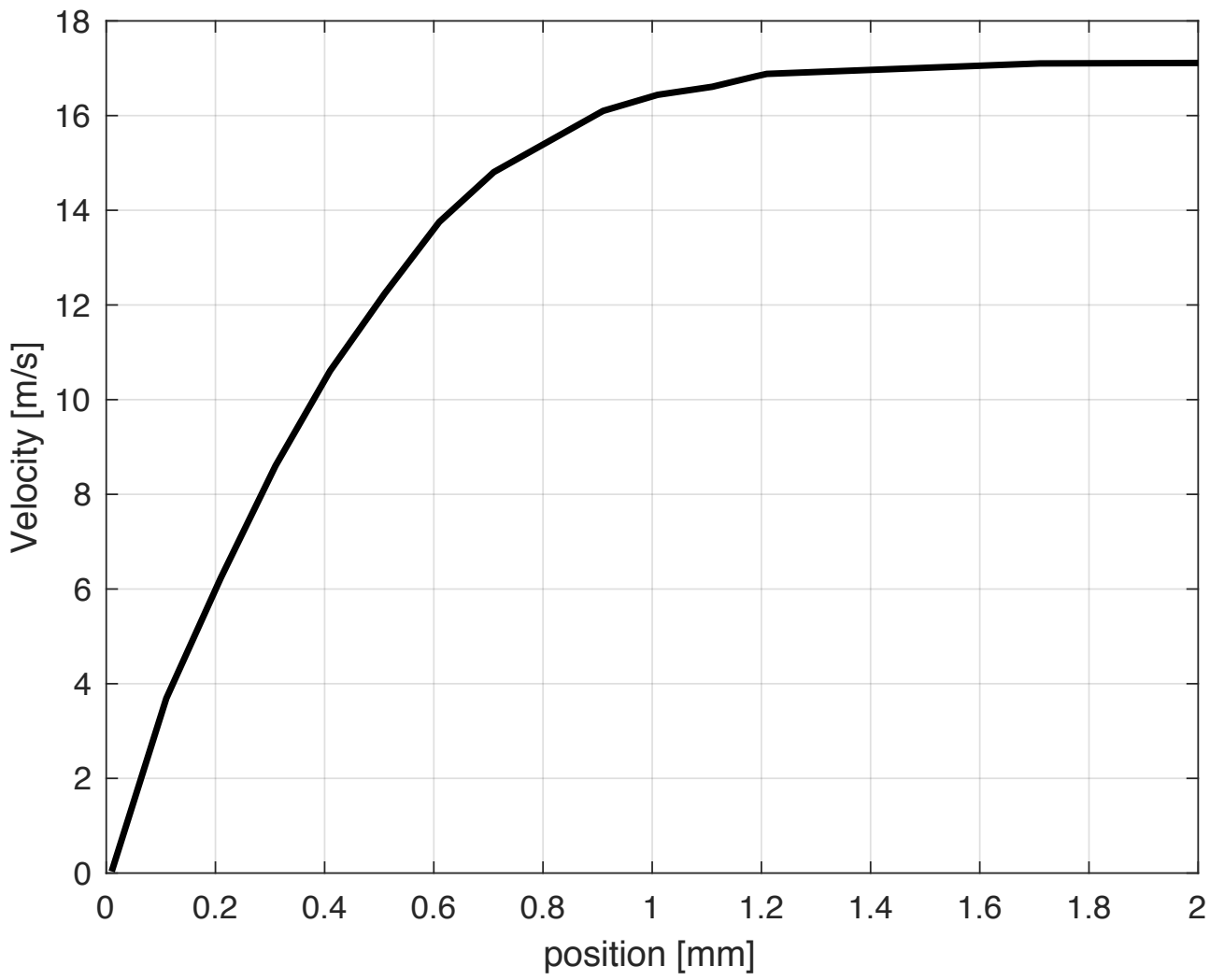




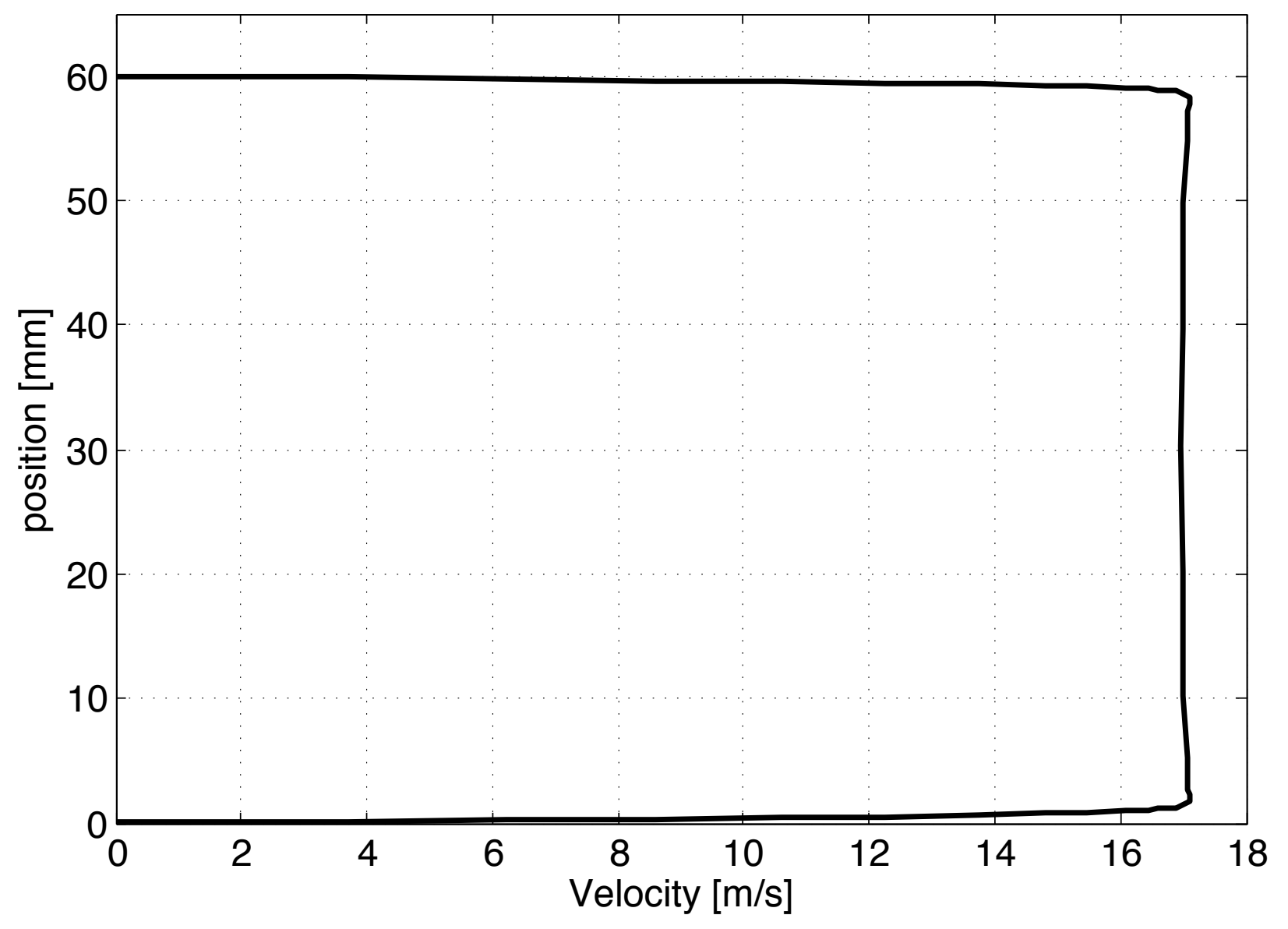




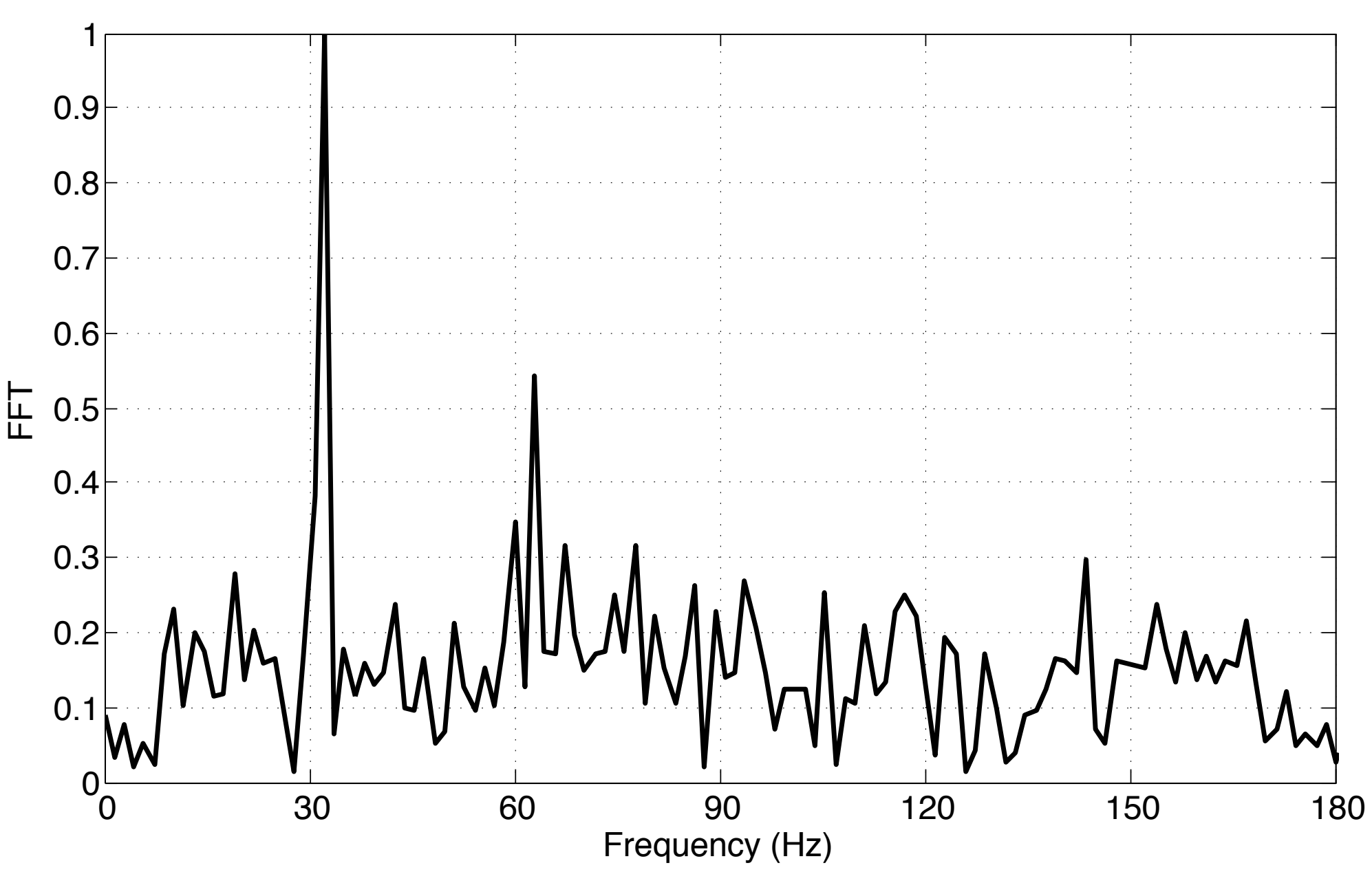




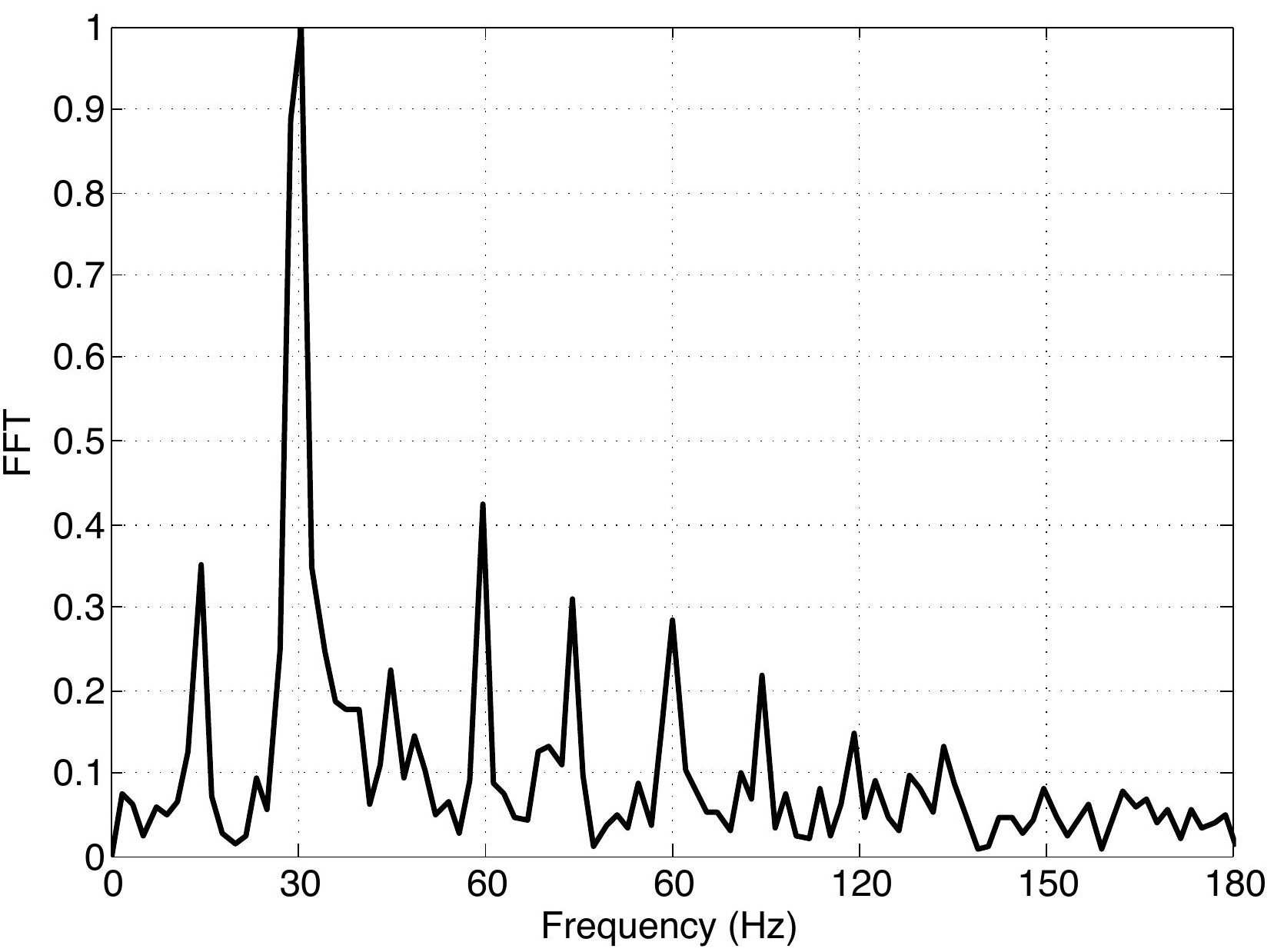




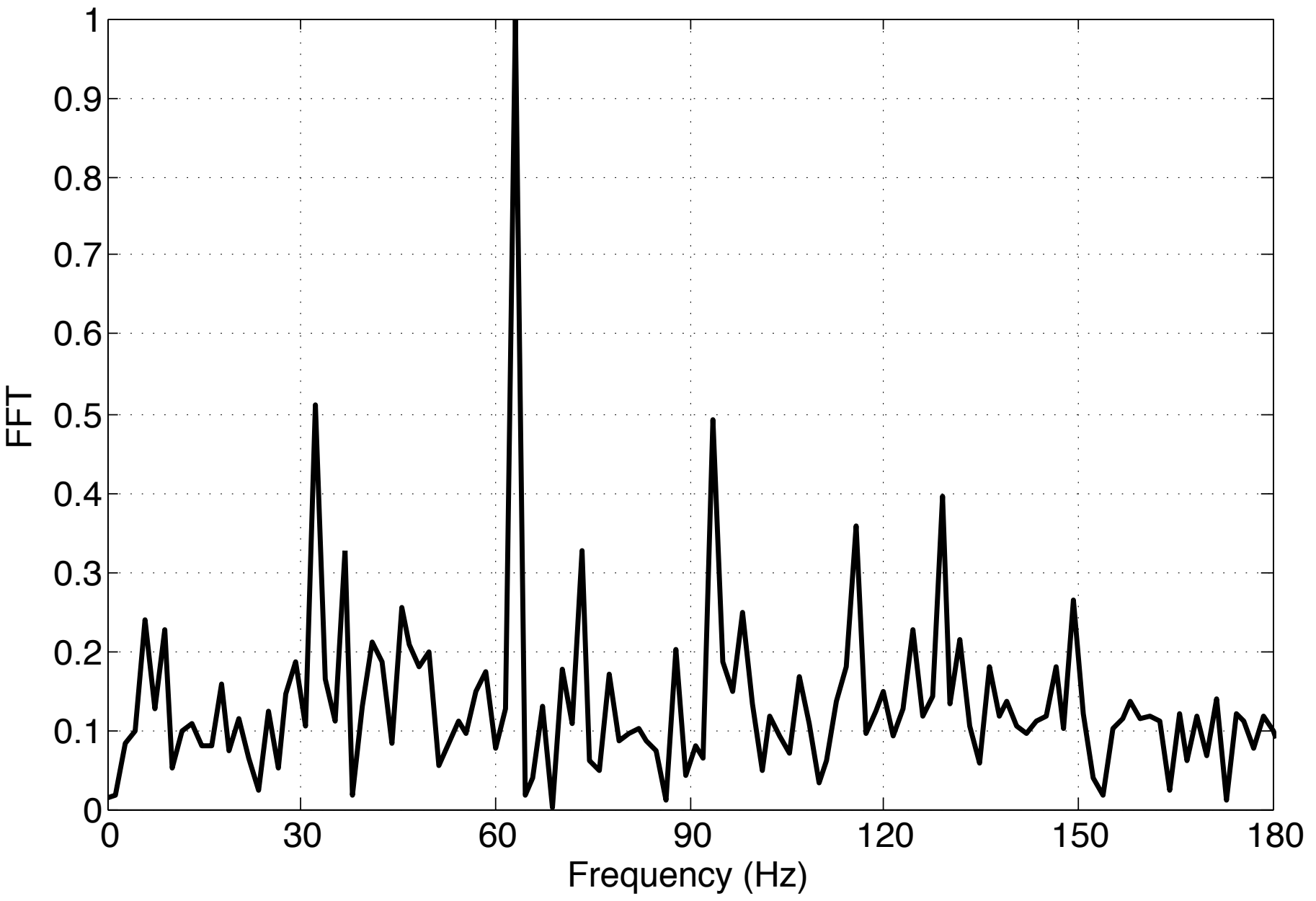




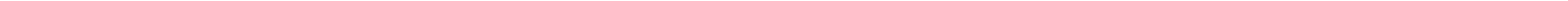




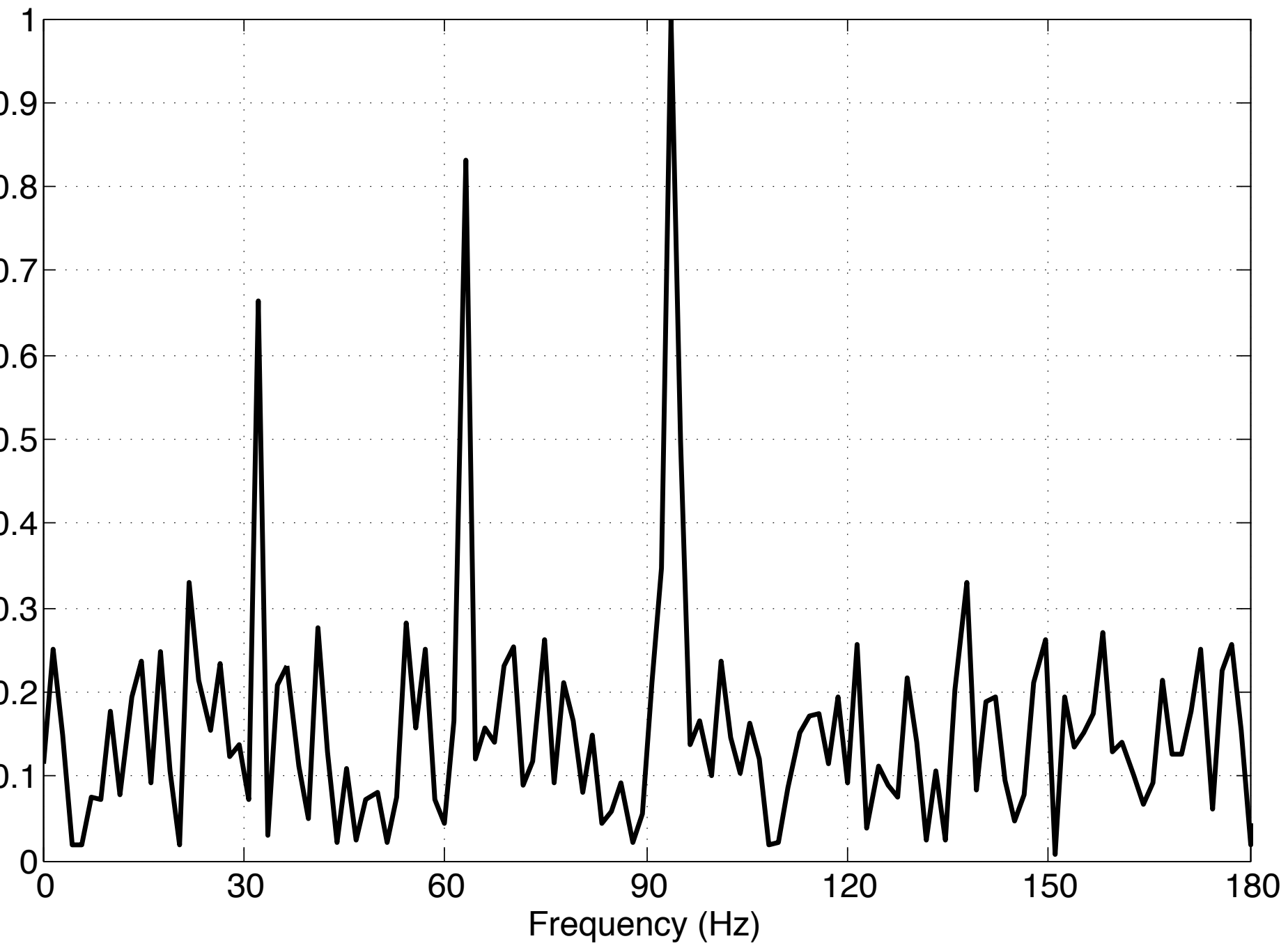




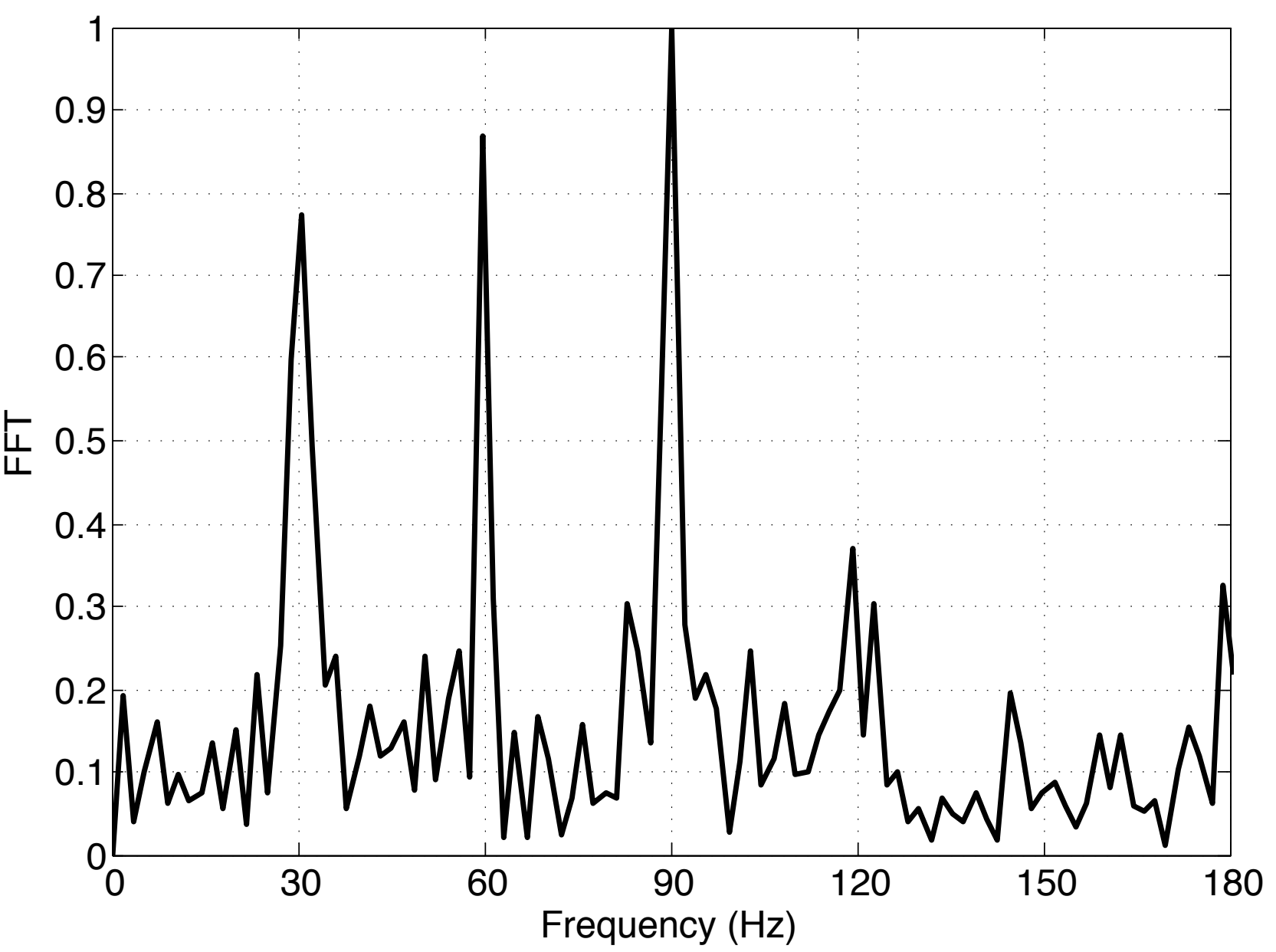




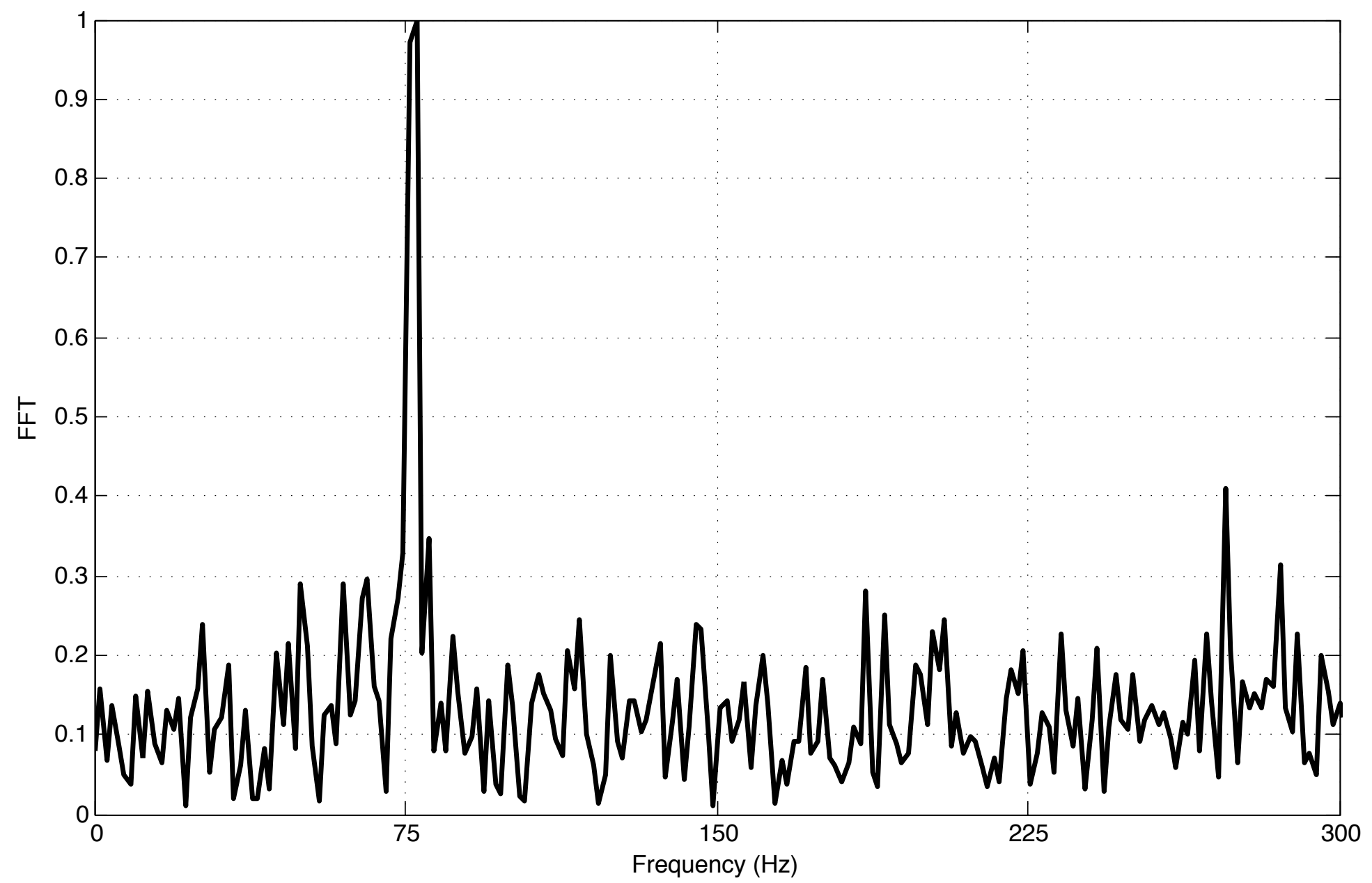




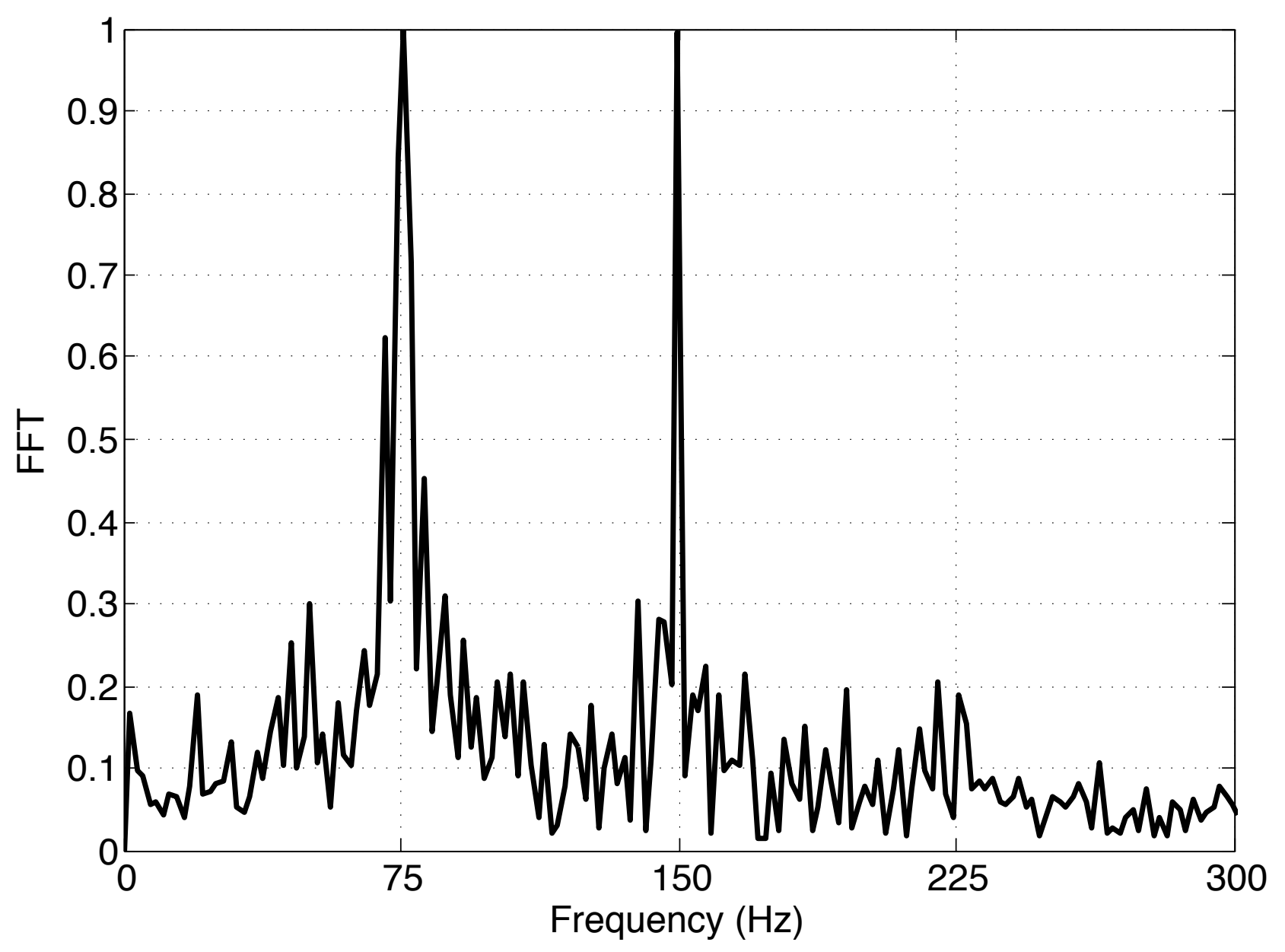

